\title{
PERANCANGAN WEBSITE SIKANGBEJO (SISTEM INFORMASI KAMPUNG KANGKUNG SUMBER REJO) PADA KAMPUNG KANGKUNG SUMBER REJO
}

\author{
Muhammad Gilvy Langgawan Putra' ${ }^{1)}$, Muhammad Iqbal Firdaus ${ }^{2)}$, Dyah Mutiara Annisa Fitri ${ }^{3)}$, Lianur \\ Istiqomah $^{4)}$, Muhammad Fahri ${ }^{5)}$, Muhammad Yusuf ${ }^{(6)}$, Santi $^{7)}$ \\ ${ }^{1}$ Jurusan Matematika dan Teknologi Informasi, Institut Teknologi Kalimantan \\ gilvy.langgawan@lecturer.itk.ac.id \\ ${ }^{2}$ Program Studi Teknik Informatika, Universitas Islam Kalimantan MAB \\ m.iqbalfirdaus@uniska-bjm.ac.id \\ 3 Jurusan Matematika dan Teknologi Informasi, Institut Teknologi Kalimantan \\ 10181019@student.itk.ac.id \\ ${ }^{4}$ Jurusan Matematika dan Teknologi Informasi, Institut Teknologi Kalimantan \\ 10181035@student.itk.ac.id \\ 5 Jurusan Matematika dan Teknologi Informasi, Institut Teknologi Kalimantan \\ 10181047@student.itk.ac.id \\ ${ }^{6}$ Jurusan Matematika dan Teknologi Informasi, Institut Teknologi Kalimantan \\ 10181055@student.itk.ac.id \\ ${ }^{7}$ Jurusan Matematika dan Teknologi Informasi, Institut Teknologi Kalimantan \\ 10181074@student.itk.ac.id
}

\begin{abstract}
Abstrak
Kegiatan penjualan produk olahan kangkung di daerah Kampung Kangkung Sumber Rejo, Kecamatan Balikpapan Tengah. dilaksanakan oleh masyarakat Kampung Kangkung Sumber Rejo. Penjualan produk olahan kangkung saat ini masih secara konvensional dengan menawarkan ke tokotoko sekitar Kampung Kangkung Sumber Rejo dan pasar tradisional daerah Balikapapan. Proses penjualan produk olahan kangkung masih cukup terbatas di daerah Balikpapan. Masyarakat Balikapapan masih kurang mengetahui keberadaan Kampung Kangkung Sumber Rejo sehingga masih belum cukup luas cakupan pemasaran produk olahan Kangkung. Berdasarkan permasalahan tersebut maka dilakukan perancangan sebuah website penjualan produk olahan kangkung untuk Kampung Kangkung Sumber Rejo dengan nama SIKANGBEJO dengan menggunkan framework codignigter. Pengembambangan website ini menggunggunakan metode waterfall, yang terdiri dari enam aktifitas, yaitu requirement definition, system and software design, implementation and unit testing, integration and system testing, dan operation and maintenance. Hasil yang diperoleh dari penelitian ini yaitu website penjualan yang digolongkan menjadi tiga aktor yaitu admin, user, dan pengguna umum yang memliliki peran sesuai dengan kebutuhan masing-masing aktor. Dengan adanya website SIKANGBEJO, kegiatan pemasaran akan lebih efektif dan efisien, serta masyarakat Balikapan dapat lebih mengetahui Kampung Kangkung Sumber Rejo sehingga dapat meningkatkan omset penjualan pada Kampung Kangkung Sumber Rejo.
\end{abstract}

Kata Kunci : Kampung Kangkung Sumber Rejo, Produk olahan kangkung, SIKANGBEJO, Website.

\section{PENDAHULUAN}

Kampung Kangkung Sumber Rejo merupakan kampung penghasil kangkung segar terbaik di Balikpapan selain penghasil kangkung segara Kampung Kangkung Sumber Rejo juga memproduksi produk olahan Kangkung. Produk olahan kangkung berupa keripik kangkung, pudding kangkung, salome, dan cimi-cimi.

Dalam kegiatan pemasaran produk olahan kangkung masih dilakukan secara konvensional dengan menjual ke toko-toko sekitar Kampung Kangkung Sumber Rejo. Menurut Kotler dan Amstrong, pemasaran yaitu proses social dan 
manajerial yang dapat mengakibatkan individu ataupun sekelompokorang mendapatkan sesuatu yang mereka perlukan dengan cara penciptaan dan pertukaran timbal balik produk dan nilai dengan orang lain[1]. Hasil penjualan produk olahan kangkung ditulis dalam sebuah pelaporan bulan. Proses pelaporan masih ditulis secara manual pada sebuah buku. Sehingga pelaporan hasil penjualan masih belum dikelola dengan baik.

Saat ini perkembangan teknologi berperan penting dalam mendukung aktivitas manusia agar lebih efektif dan efisien. Perkembangan dunia teknologi memberikan dampak yang besar terhadap perkembangan sistem informasi[2]. Salah satu teknologi yang dapat membantu kegiatan manusia agar lebih efektif dan efisien yaitu sistem informasi pada bidang penjualan $(E$ Commerce). Menurut Barkattulla (2005) penjualan berbasis web (E-Commerce) mempunyai peluang berhasil dalam bisnis melaui dunia maya[3]. Melalui dunia maya proses penjualan produk olahan kangkung dapat dilakuka kapan saja dan dimana saja, serta cakupan pemasaran dapat lebih luas. Dalam mendukung penjualan maka dibutuhkan suatu software pendukung.

Menurut langer (2008) software yaitu abstraksi fisik yang dapat membantu kita berbicara dengan mesin hardware. Tanpa adanya software, hardware yang diciptakan tidak dapat berguna atau berfungsi dengan optimal[2].

Menurut Jauhari (2010) bidang bisnis perdagangan yang berkembang pada saat ini berpengaruh besar terhadap penggunaan internet. Dengan adanya internet proses pemasaran jauh lebih mudah dilakukan[1].

Perkembangan teknologi tersebut dalam bidang sistem informasi diharapkan dapat mendukung kemajuan masyarakat Kampung Kangkung Sumber Rejo dalam bidang pemasaran produk olahan kangkung, sehingga dapat mempermudah masyarak dalam memperkenalkan produk olahan kangkung secara luas di daerah Balikapan. Sistem Informasi ini dapat diwujudkan berupa website penjualan produk olahan kangkung yang disebut dengan SIKANGBEJO.
Langkah utama yang perlu dilakuakan sebelum melakukan perancangan website SIKANGBEJO dilakukan tahap pengamatan langsung atau observasi bertujuan untuk mengananlisis masalah. Tahap selanjutnya melakukan wawancara kepada pihak terkat untuk mendapatkan informasi secara lengkap dan akurat, hal ini dapat menjadi bahan pertimbangan bagi pengembang website dalam merancang website SIKANGBEJO[4].

Website merupakan penyediakan berbagai informasi, pada umumnya website ditujukkan berdasarkan URL, website berguna untuk menyediakan informasi individual, kelopok, organisasi ataupun lembaga. Website responsive merupakan teknik yang digunakan dalam pembuatan layout berdasarkan device[5].

Perancanganan suatu website menggunakan Bahasa markup yang disebut dengan HTML (Hypertext Markup Language). HTML (Hypertext Markup Language) diciptakan oleh tim Berners-Lee pada saat berkerja di CERN dan dipopulerkan oleh browse Mosaic[6].

Pengembangan SIKANGBEJO ini dilakukan dengan menggunakan framework codeignigter. Menurut Prabowo (2015) codeignigter adalah framework yang digunakan dalam perancangan website dengan menggunakan HTML. Adapun keunggulan codeignigrter yaitu dapat membangun website yang kompleks sehingga dapat mempersingkan perancangan website karena kebutuhan pengembang seperti subclass dan modul telah tersedia[7].

Website membutuhkan suatu basis data dalam mendukung fungsinya. Basis data yaitu sistem yang terdapat data-data didalamnya data tersebut saling memiliki keterkaitan pada program yang dirancang, program dapat mengakses data-data ini sebagai Pendukung sempurnanya berjalan suatu program sesuai kebutuhan individu atau kelompok[8].

Melakukan perancangan website penjualan produk olahan kangkung menggunakan model SDLC (System Life Cycle). Menurut Rosa (2013) SDLC (System Life Cycle) yaitu suatu proses untuk mengembangkan perangkat lunak. Terdapat tahapan dalam SDLC (System Life Cycle) yang terdiri dari pembuatan proposal, melakukan pengembangan sistem, melakukan 
perancangan sistem, analisa kebutuhan sistem, desain sistem, pengujian sistem, implementasi sistem, pemeliharaan sistem dan diposisi sitem[9].

Metode waterfall merupakan metode pengembangan yang terdiri dari beberapa tahapan yaitu requiremet definition, system and software design, implementation and unit testing, integration and system testing, dan operation and maintenance.

UML (Unified Modelling Language) merupakan sekumpulan peralatan pada umumnya berupa diagram yang berguna dalam memodelkan sistem berkerja atau berinteraksi [10]. Pemodelan yang digunakan pada perancangan SIKANGBEJO menggunakan use case, class diagram, dan entity relation diagram.

Use Case menjelaskan terkait aktifitas yang dikerjaan oleh aktor, use case dimodelkan dalam bentuk elips horizontal. Class diagram memodelkan suatu sistem, sekaligus memberikan layanan dalam suatu keadaan. Entity relation diagram menjelasakan keterkaitan antar tabeltabel, entity relation diagram berguna dalam mengatur database sebuah sistem[11].

\section{METODE PENELITIAN}

Metode pengumpula data yang digunakan penulis dalam melakukan perancangan SIKANGBEJO yaitu :

a. Observasi

Pada tahap observasi penulis melakukan pengamatan langsung mengenai proses penjualan produk olahan kangkung di Kampung Kangkung Sumber Rejo yang dilakukan oleh warga sekitar.

b. Wawancara

Pada tahap wawancara penulis melakukan wawancara kepada Ibu Sugi selaku penanggung jawab produk olahan kangkung di Kampung Kangkung Sumber Rejo.

c. Studi Pustaka

Pada tahap studi pustaka penulis malakukan pencarian referansi dari berbagai buku dan jurnal untuk memenuhi kebutuhan dilaksanakan penelitian.

Metode pengembangan Sistem Informasi Kampung Kangkung Sumber Rejo
(SIKANGBEJO) menggunakan model SDLC (System Development Life Cycle) menggunakan metode Waterfall.

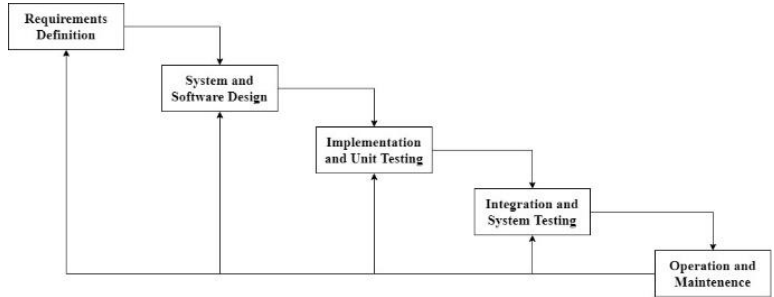

Gambar 1. Metode Waterfall

a. Requirements Definition

Requirement definition yaitu kegiatan awal yang dilakukan oleh pengembang aplikasi yaitu dimana pengembang melakukan analisis data, mendefinisikan sistem mulai dari layanan pada sistem, batasan-batasan dari sistem dan tujuan perancangan sistem ditetapkan melalui konsultasi bersama stakeholder. Pada tahap requirement system hasil yang didapatkan yaitu rincian dan spesifikasi sistem sesuai kebutuhan stakeholder.

b. System and Software Design

System and software design yaitu tahap menganalisis kebutuhan user dan admin Kampung Kangkung Sumber Rejo. Pada tahap ini menentukan spesifikasi hardware dan software, dengan membentuk desain sistem keseluruhan. Tahap perancangan software berkaitan dengan identifikasi dan permodelan abstraksi sistem dasar software dan keterkaitannya. Setap hubungan sistem dijelaskan dan diidentifikasi secara rinci.

c. Implementation and Unit Testing

Pada tahap Implementation and Unit Testing yaitu tahap implementasi perangkat lunak yang diwujudakan berupa kode program. Dilakukannya pemprograman dengan menggunakan PHP pada sublime text, serta dibuatnya script agar dapat mengakses database MySQL. Unit Testing dilakukan yaitu untuk memverifikasi apakah setiap unit telah memenuhi spesifikasi yang telah direncanakan.

d. Integration and System Testing

Tahap Integration and system testing yaitu tahap melakukan integrase unit sebagai suatu sistem yang lengkap untuk memastikan 
persyaratan ataupun spesifikasi software yang dibuat telah terpenuhi. Apabila terdapat hasil yang tidak sesuai maka akan kembali ke proses system and software design untuk melakukan perbaikan.Setelah pengujian berhasil maka software dapat dikirm ke customer.

e. Operation and Maintenance

Operation and maintenance yaitu fase terakhir, fase ini paling panjang yaitu dimana sistem diimplementasikan atau dimanfaatkan secara langsung. Pada proses Maintenance yaitu tahap perbaikan jika terjadi kesalahankesalahan yang belum didapatkan pada tahap sebelum maintenance, tahap ini berguna dalam meningkatkan kinerja unit sistem.

\section{HASIL DAN PEMBAHASAN}

Adapun hasil dan pembahasan berdasarkan hasil yang didapatkan oleh penulis.

\section{a. Lingkup masalah}

Perangkat lunak SIKANGBEJO merupakan sebuah sistem yang dibuat untuk memudahkan pembeli maupun penjual produk kangkung di Kampung Kangkung Sumber Rejo. Adapun lingkup masalah yang ditangani oleh SIKANGBEJO antara lain:

1. Sistem mampu memberikan rekomendasi olahan kangkung yang paling diminati, yaitu sistem dapat menyortir olahan kangkung berdasarkan minat user.

2. Sistem mampu menghitung rating atau penilaian pada produk olahan kangkung, yaitu sistem dapat mengkalkulasi nilai yang diberikan oleh user.

3. Sistem mampu menyajikan pesanan saya yang dapat membantu user dalam mencatat riwayat pembelian.

4. Sistem mampu mengkategorikan jenis olahan kangkung, yaitu terdapat dua jenis olahan kangkung: frozen, dan kering.

5. Sistem mampu menampung produk-produk yang akan dibeli dengan adanya fitur keranjang.

\section{b. Analisa Kebutuhan}

Berdasarkan lingkup masalah yang telah dijabarkan maka dirancang fungsi utama perangkat lunak sebagai berikut.
1. Memberikan fitur rekomendasi olahan kangkung berdasarkan hasil penjualan olahan kangkung yang paling banyak diminati.

2. Memberikan fitur rating atau penilaian bagi user pada produk olahan kangkung.

3. Memberikan fitur riwayat pembelian pesanan pada user untuk hasil pembelian olahan kangkung yang telah dibeli oleh user

4. Memberikan fitur kategori berdasarakan jenis olahan kangkung dimana user dapat melihat dan membeli jenis olahan kangkung apa saja dan admin akan meng-update atau memginputkan data datanya

5. Memberikan fitur keranjang pada user untuk menampung terlebih dahulu pesanan oleh user sebelum membeli/checkout produk.

Kebutuhan fungsional menjelaskan kebutuhan fungsional dari SIKANGBEJO yang didefinisikan berdasarkan kode fungsinya, kebutuhan fungsional dibagi berdasarkan aktor yang terlibat yang terdiri dari admin, user, dan pengguna umum.

Tabel 1. Kebutuhan Fungsional Admin

\begin{tabular}{cl}
\hline \multicolumn{1}{c}{ Kode Fungsi } & Nama Fungsi \\
\hline SRS_F-SIKANGBEJO-001 & $\begin{array}{l}\text { Menambah } \\
\text { data produk } \\
\text { Mengubah } \\
\text { data produk } \\
\text { SRS_F-SIKANGBEJO-002 }\end{array}$ \\
SRS_F-SIKANGBEJO-003 & $\begin{array}{l}\text { Menghapus } \\
\text { data produk } \\
\text { Melihat data } \\
\text { produk }\end{array}$ \\
SRS_F-SIKANGBEJO-004 & $\begin{array}{l}\text { Mengkategori } \\
\text { kan produk } \\
\text { SRS_F-SIKANGBEJO-005 }\end{array}$ \\
SRS_F-SIKANGBEJO-006 & $\begin{array}{l}\text { Melihat data } \\
\text { user } \\
\text { Menghapus } \\
\text { data user } \\
\text { Menambahkan } \\
\text { data admin } \\
\text { SRS_F-SIKANGBEJO-007 } \\
\text { SRS_F-SIKANGBEJO-008 }\end{array}$ \\
SRS_F-SIKANGBEJO-009 & $\begin{array}{l}\text { data admin } \\
\text { Mengubah } \\
\text { data admin } \\
\text { LogOut }\end{array}$ \\
SRS_F-SIKANGBEJO-010 & \\
SRS_F-SIKANGBEJO-011 &
\end{tabular}

Tabel 2. Kebutuhan Fungsional User Kode Fungsi Nama Fungsi 


\begin{tabular}{|c|c|}
\hline SRS_F-SIKANGBEJO-012 & Melihat produk \\
\hline SRS_F-SIKANGBEJO-013 & $\begin{array}{l}\text { Menambahkan } \\
\text { produk }\end{array}$ \\
\hline SRS_F-SIKANGBEJO-014 & $\begin{array}{l}\text { Menghapus } \\
\text { produk }\end{array}$ \\
\hline SRS_F-SIKANGBEJO-015 & $\begin{array}{l}\text { Menyimpan } \\
\text { produk } \\
\text { sementara }\end{array}$ \\
\hline SRS_F-SIKANGBEJO-016 & $\begin{array}{l}\text { Menambahkan } \\
\text { rating }\end{array}$ \\
\hline SRS_F-SIKANGBEJO-017 & $\begin{array}{l}\text { Melihat riwayat } \\
\text { pembelian } \\
\text { produk }\end{array}$ \\
\hline SRS_F-SIKANGBEJO-018 & $\begin{array}{l}\text { Melihat } \\
\text { ketersedian } \\
\text { produk }\end{array}$ \\
\hline SRS_F-SIKANGBEJO-019 & $\begin{array}{l}\text { Menambahkan } \\
\text { jumlah } \\
\text { pembelian }\end{array}$ \\
\hline SRS_F-SIKANGBEJO-020 & $\begin{array}{l}\text { Mengurangi } \\
\text { jumlah } \\
\text { pembelian }\end{array}$ \\
\hline SRS_F-SIKANGBEJO-021 & $\begin{array}{l}\text { Membatalkan } \\
\text { pembelian } \\
\text { produk }\end{array}$ \\
\hline SRS_F-SIKANGBEJO-022 & $\begin{array}{l}\text { Mengubah data } \\
\text { profile akun }\end{array}$ \\
\hline SRS_F-SIKANGBEJO-023 & $\begin{array}{l}\text { Mengganti } \\
\text { password akun }\end{array}$ \\
\hline SRS_F-SIKANGBEJO-024 & $\begin{array}{l}\text { Menghubungi } \\
\text { admin }\end{array}$ \\
\hline SRS_F-SIKANGBEJO-011 & Log Out \\
\hline
\end{tabular}

Tabel 3. Kebutuhan Fungsional Pengguna Umum

\begin{tabular}{cl}
\hline \multicolumn{1}{c}{ Kode Fungsi } & \multicolumn{1}{c}{ Nama Fungsi } \\
\hline SRS_F-SIKANGBEJO-025 & $\begin{array}{l}\text { Mengakses } \\
\text { SIKANGBEJO }\end{array}$ \\
SRS_F-SIKANGBEJO-026 & Login \\
SRS_F-SIKANGBEJO-027 & $\begin{array}{l}\text { Melihat } \\
\text { tampilan SI } \\
\text { SRS_F-SIKANGBEJO-028 }\end{array}$ \\
\hline
\end{tabular}

Selain kebutuhan fungsional terdapat juga kebutuhan nonfungsional pada SIKANGBEJO.

Tabel 4. Kebutuhan Nonfungsional

\begin{tabular}{cl}
\hline \multicolumn{1}{c}{ Kode } & \multicolumn{1}{c}{ Parameter } \\
\hline SRS_NF-SIKANGBEJO-001 & Ketersediaan \\
SRS_NF-SIKANGBEJO-002 & Kapasitas \\
SRS_NF-SIKANGBEJO-003 & Performa \\
SRS_NF-SIKANGBEJO-004 & Keamanan \\
SRS_NF-SIKANGBEJO-005 & Kehandalan \\
SRS_NF-SIAKNGBEJO-006 & Kemudahan \\
SRS_NF-SIKANGBEJO-007 & Kompabilitas \\
SRS_NF-SIKANGBEJO-008 & Tampilan \\
\hline
\end{tabular}

SIKANGBEJO merupakan sistem informasi penjualan produk olahan kangkung yang menggunakan ruang lingkup berbasis web, pengguna harus terhubung melalui jaringan internet untuk dapat melakukan akses pada website. SIKANGBEJO menggunakan kerangka kerja HTML dan bahasa pemrograman PHP. SIKANGBEJO menggunakan lingkungan sistem sebagai berikut:

1. Server
a. Server menggunakan XAMPP v.3.2.2.
b. Sistem Operasi menggunakan windows 10 64 bit.
c. RAM pada computer server sebesar 4 GB DDR 4.
d. Processor Intel pentium silver N5000 1.10 $\mathrm{GHz}-2.70 \mathrm{GHz}, 4 \mathrm{MB}$.
e. Menggunakan DBMS MySQL.

2. Client

Client mampu mengakses pada website SIKANGBEJO meng-gunakan sistem operasi windows, linux, apple, dan perangkat mobile seperti android, windows phone. Untuk browser dapat menggunakan Google Chrome, Opera Mini, Safari, Internet Explorer, dan lain-lain.

\section{c. Perancangan Sistem}

Perancangan SIKANGBEJO menggunakan use case diagram, class diagram, dan entity relation diagram.

\section{Use Case Diagram}




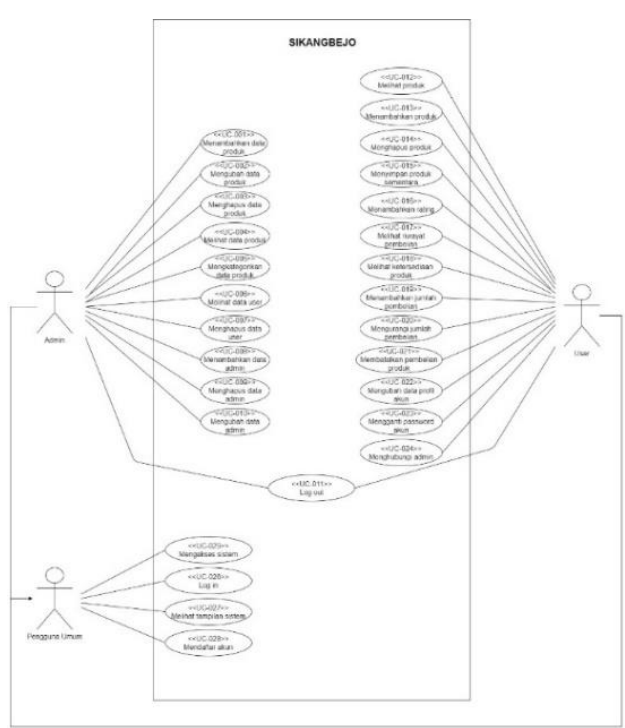

Gambar 2. Use Case Diagram

\section{Class Diagram}

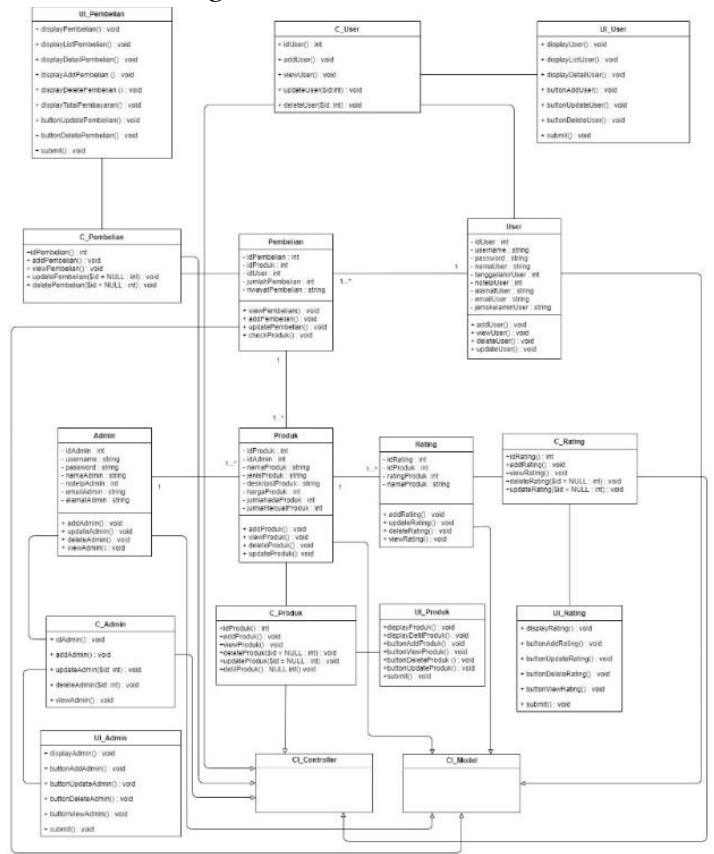

Gambar 3. Class Diagram

\section{Entity Relation Diagram}

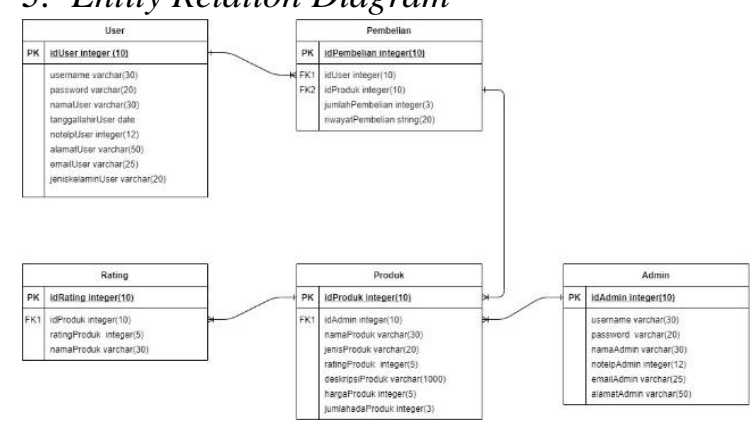

Gambar 4. Entity Relation Diagram

\section{d. Implementasi Desain dan Perancangan}

Pada tahap implementasi dan desain perancangan, website SIKANGBEJO didapatkan hasil sebagai berikut.

1) Login

Login merupakan halaman awal ketika mengakses SIKANGBEJO. Admin ataupun user dapat mengisi alamat email dan password.

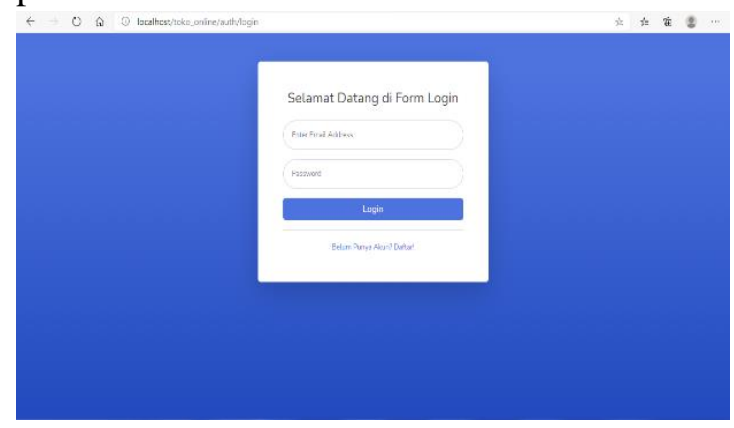

Gambar 5. Login

Jika admin ataupun user belum memiliki akun dapat melaukan pendaftaran akun terlebih dahulu dengan mengisi nama lengkap, username, dan password yang ingin digunakan.

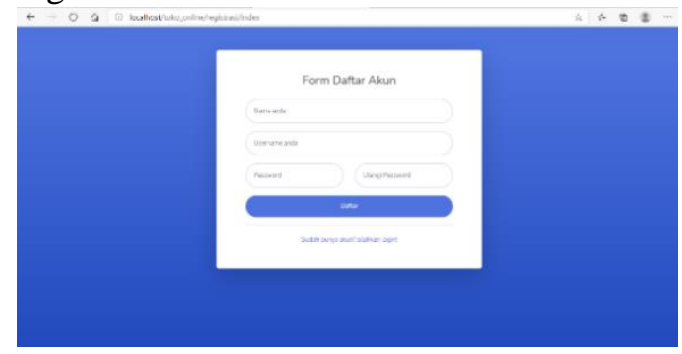

Gambar 6. Form Pendaftaran

2) Menambahkan data produk

Pada halaman menambah data produk dilakukan oleh admin yang mengisi data-data produk olahan kangkung yang akan dipasarkan beserta keterangan lengkap mengenai produk penjualan mulai dari nomor produk, nomor admin, nama produk, jenis produk, deskripsi produk, harga produk, jumlah produk, dan jumlah produk yang telah terjual. 


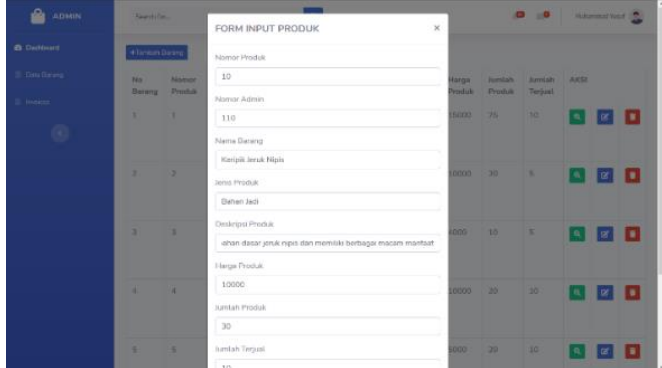

Gambar 7. Menambah Data Produk

3) Data produk pada halaman admin

Pada halaman admin dapat melakukan tindakan seperti mengubah, menghapus, dan melihat produk.

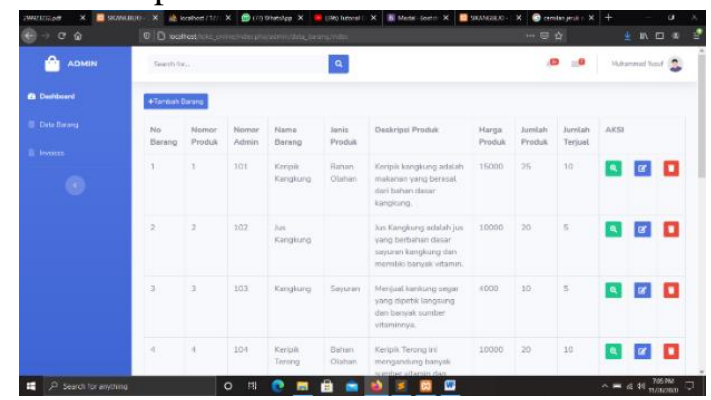

Gambar 8. Mengubah, menghapus, dan melihat data produk

4) Dashboard

Tampilan setelah melakukan login user berada di menu dashboard, user melihat daftar produk-produk olahan kangkung. Setiap produk disertai dengan informasi lengkap dengan menekan tombol detail dan dapat memasukkan produk ke dalam keranjang dengan menekan tombol tambah ke keranjang.

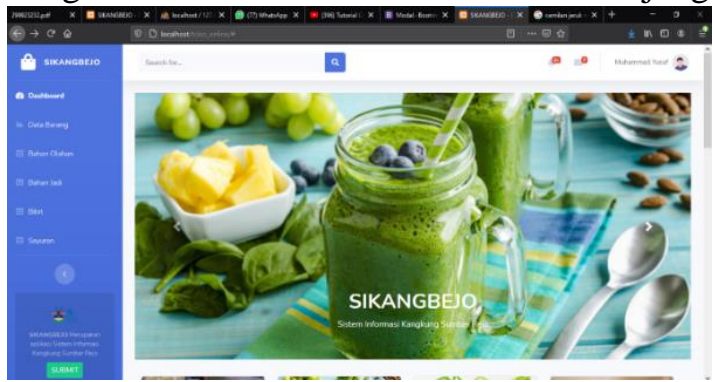

Gambar 9. Dashboard

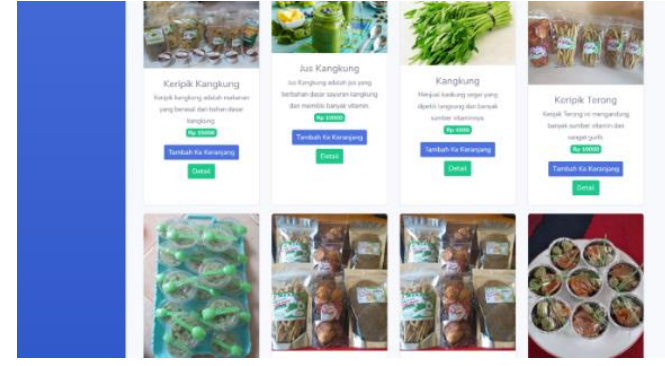

Gambar 10. Dashboard

5) Keranjang Belanja

Pada fitur keranjang belanja user dapat menambahkan produk, mengubah data produk, menghapus produk, dan menyimpan produk sementara.

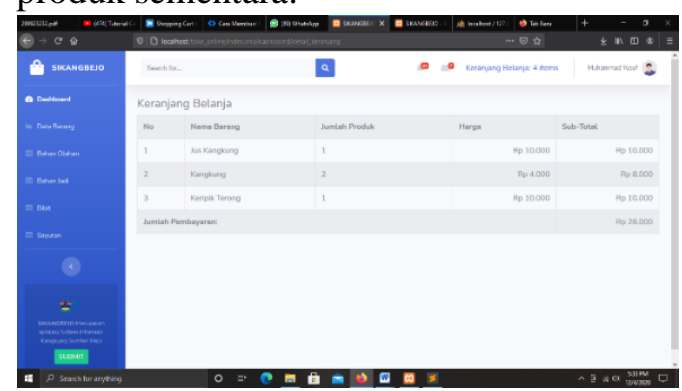

Gambar 11. Mengola Data Produk

Menyimpan produk sementara, melihat riwayat pembelian produk, mengurangi jumlah pembelian, membatalkan pembelian produk.

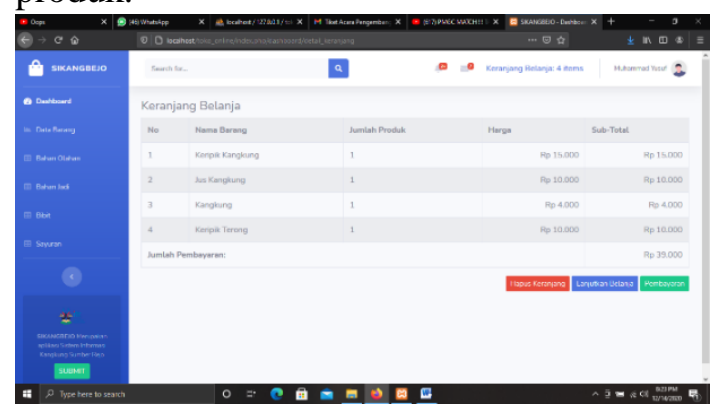

Gambar 12. Mengelola Data Produk

6) Menambahkan jumlah pembelian.

User dapat menambahkan jumlah pembelian dengan memilih produk dan selanjutnya menekan tombol submit. 


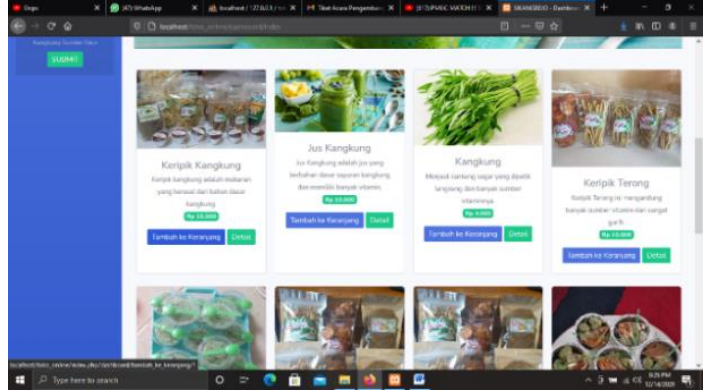

Gambar 13. Dashboard User

7) Tampilan melihat data user

Pada tampilan admin dapat melihat data user, yang menyediakan informasi id, nama pelanggan, tempat dan tanggal lahir, dan tampilan ini menyediakan tombol aksi yang dapat dilakukan admin.
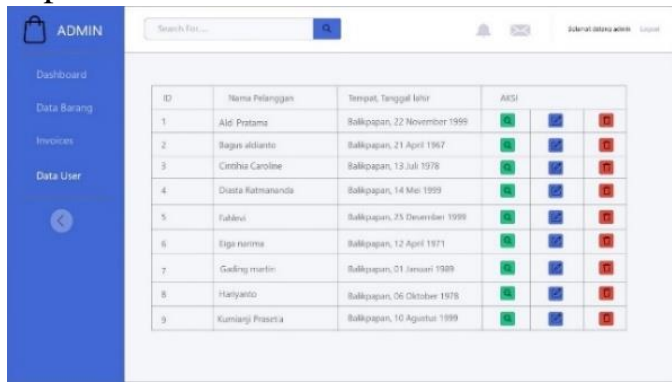

Gambar 14. Data User

\section{e. Pengujian Perangkat Lunak}

Tahap pengujian perangkat lunak berguna untuk mengetahui kemampuan dari program SIKANGBEJO yang telah berhasil dirancang agar sesuai dengan renca awal dan kebutuhan pengguna. Berikut merupakan flow graph pengujian perangkat lunak.

1) Fitur Pembayaran

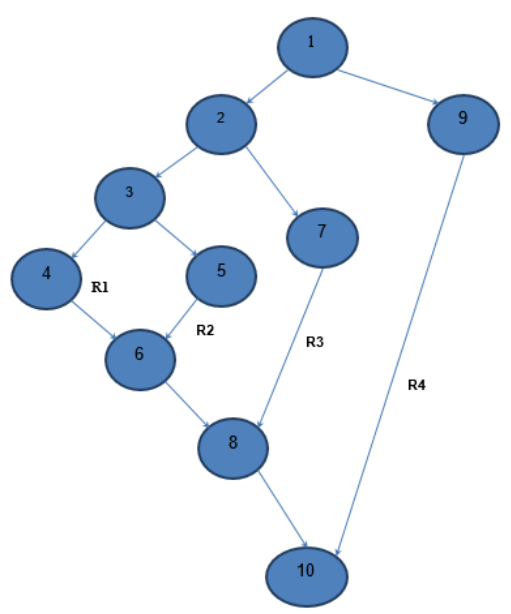

Gambar 15. Flow Graph Fitur Pembayaran
Jalur Independent :

1) $1-9-10$;

2) $1-\underline{2}-\underline{7}-\underline{8}-10$;

3) $1-2-\underline{3}-\underline{4}-\underline{6}-8-10$;

4) $1-2-3-\underline{5}-6-8-10$;

Perhitungan Cyclomatic Complexity / V(G) :

- $\mathrm{V}(\mathrm{G})=4$ Region

- $\mathrm{V}(\mathrm{G})=\mathrm{E}-\mathrm{N}+2=12-10+2=4$

- $\mathrm{V}(\mathrm{G})=\mathrm{P}+1=3+1=\mathbf{4}$

2) Fitur Menambah Produk pada Keranjang

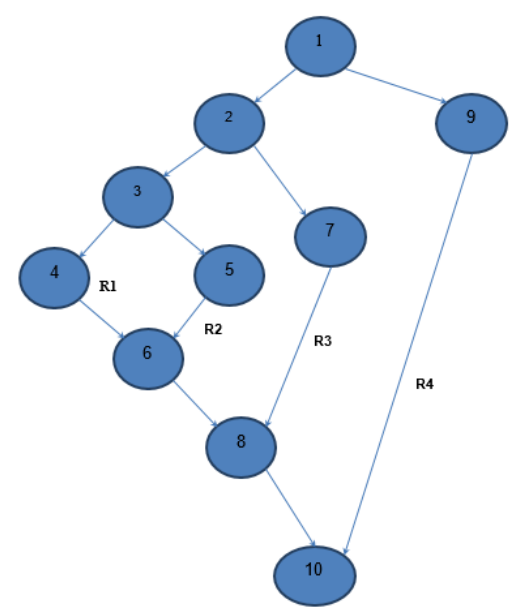

Gambar 16. Flow Graph Fitur Menambah Produk pada Keranjang

Jalur Independent :

1) $1-9-10$;

2) $1-\underline{2}-\underline{7}-\underline{8}-10$;

3) $1-2-\frac{3}{3}-\underline{4}-6-8-10$;

4) $1-2-\overline{3}-\underline{5}-6-8-10$;

Perhitungan Cyclomatic Complexity / V(G) :

- $\mathrm{V}(\mathrm{G})=4$ Region

- $\mathrm{V}(\mathrm{G})=\mathrm{E}-\mathrm{N}+2=12-10+2=4$

- $\mathrm{V}(\mathrm{G})=\mathrm{P}+1=3+1=\mathbf{4}$

3) Pengujian Akhir

Tabel 5. Pengujian Akhir

\begin{tabular}{lc}
\hline \multicolumn{1}{c}{ No Req } & Status \\
\hline SRS_F-SIKANGBEJO-005 & Valid \\
SRS_F-SIKANGBEJO-001 & Valid \\
SRS_F-SIKANGBEJO-001 & Valid \\
SRS_F-SIKANGBEJO-001 & Valid \\
SRS_F-SIKANGBEJO-013 & Valid \\
SRS_F-SIKANGBEJO-013 & Valid \\
SRS_F-SIKANGBEJO-013 & Valid \\
SRS_NF-SIKANGBEJO-002 & Valid \\
SRS_NF-SIKANGBEJO-003 & Valid \\
\hline
\end{tabular}




\section{KESIMPULAN}

Sistem Informasi Kampung Kangkung Sumber Rejo (SIKANGBEJO) dapat membantu masyarakat Kampung Kangkung Sumber Rejo dalam melakukan pemasaran produk olahan kangkung, selain itu juga dapat membantu masyarakat dalam hal mengatur data-data penjualan. Dengan adanya fitur detail produk customer tidak perlu bertanya lagi kepada pejual, sehingga hal ini sangat memudahkan dan mengefisienkan bagi penjual produk olahan kangkung dan pembeli produk olanhan kangkung.

\section{REFERENSI}

[1] S. K. Dewi and A. K. Garside, "Perancangan Website Sebagai Media Promosi Dan Penjualan Pada Home Industry Abon," J. Tek. Ind., vol. 15, no. 2, 2014.

[2] Y. I. Maulana, "Perancangan Perangkat Lunak Sistem Informasi Pendataan Guru Dan Sekolah (SINDARU) Pada Dinas Pendidikan Kota Tangerang Selatan," J. Pilar Nusa Mandiri, vol. 13, no. 1, 2017.

[3] A. Supriyanto, Burhan, and M. Ulya, "Perancangan Sistem Informasi Penjualan Berbasis Web Di Pt . Garam ( Persero )," J. Argointek, vol. 7, no. 2, 2013, [Online]. Available:

http://pertanian.trunojoyo.ac.id/wpcontent/uploads/2014/04/Jurnal-5.pdf.

[4] D. S. Purnia, A. Rifai, and S. Rahmatullah, "Penerapan Metode Waterfall dalam Perancangan Sistem Informasi Aplikasi Bantuan Sosial Berbasis Android," Semin. Nas. Sains dan Teknol. 2019, pp. 1-7, 2019.
[5] Kamaruddin Tone, "Untuk perancangan proses digambarkan menggunakan DFD (," J. Instek, vol. 1, no. 1, pp. 50-60, 2016.

[6] D. Lavarino and W. Yustanti, "No Title Ramcang Bangun E-Voting Berbasis Website di Universitas Surabaya," $J$. Manajem Inform., vol. 6, 2016.

[7] A. Asroni, "Penerapan Model View Controller (MVC) Dengan Framework Codeigniter Pada Sistem Informasi Booking Wisata Klangon," BERDIKARI J. Inov. dan Penerapan Ipteks, vol. 6, no. 2, pp. 119-130, 2018, doi: 10.18196/bdr.6239.

[8] T. Andrasto, "Pengembangan Sistem Database Hasil Penelitian Dan Pengabdian Kepada Masyarakat Dosen Unnes," J. Tek. Elektro Unnes, vol. 5, no. 2, 2013, doi: 10.15294/jte.v5i2.3556.

[9] D. W. T. Putra and R. Andriani, "Unified Modelling Language (UML) dalam Perancangan Sistem Informasi Permohonan Pembayaran Restitusi SPPD," J. TeknoIf, vol. 7, no. 1, p. 32, 2019, doi: 10.21063/jtif.2019.v7.1.32-39.

[10] H. Sensen and U. E. Unggul, "Pemodelan Sistem Menggunakan UML ( Unified Modelling Language )," Syst. Model., no. July, pp. 0-5, 2019.

[11] A. Sasongko, "Sistem Informasi Geografis Berbasis Web Untuk Pemetaan Jalan Dan Bangunan," J. Khatulistiwa Inform., vol. 4, no. 1, 2016, [Online]. Available: https://ejournal.bsi.ac.id/ejurnal/index.php /khatulistiwa/article/view/1252/1017. 